\title{
Androgenic and Antiandrogenic Effects of Alkylphenols and Parabens Assessed Using the Reporter Gene Assay with Stably Transfected CHO-K1 Cells (AR-EcoScreen System)
}

\author{
Kanako Satoh, ${ }^{*}$ Rhouichi Nonaka, Ken-ichi Ohyama, and Fumiko Nagai \\ Department of Environmental Health and Toxicology, Tokyo Metropolitan Institute of Public Health, 24-1 Hyakunincho 3-chome, \\ Shinjuku-ku, Tokyo 169-0073, Japan
}

(Received May 10, 2005; Accepted July 11, 2005)

\begin{abstract}
An androgen receptor (AR)-reporter gene assay for some chemicals was examined using two different types of stably transfected CHO-K1 cell lines (AR-EcoScreen cells for androgenic activity and c-luc cells for cell toxicity evaluation). One stably expresses luciferase with androgen induction. The other stably expresses it without the need for androgen induction. We studied the responsiveness of the luciferase of AR-EcoScreen to androgen agonists and androgen antagonists. The luciferase activity of AR-EcoScreen was highly induced by androgens such as $5 \alpha-$ dihydroxytestosterone and testosterone. Furthermore, the luciferase activity of AR-EcoScreen was very susceptible to androgen antagonists such as hydroxyflutamide and cyproproterone acetate compared with that of MDA-kb2, which stably expresses androgen and glucocorticoid-responsive luciferase and represents a tool for screening for androgenicity. We examined the AR-reporter gene assay of some chemicals containing alkylphenols and parabens using AR-EcoScreen and c-luc cells (AR-EcoScreen system). None of the tested chemicals had any androgenic activity. However, 4- - -octylphenol, 4- $n$-dodecylphenol, 4- $n$-nonylphenol, 4- $n$-hexylphenol, 4- $n$-pentylphenol, 4- $n$ octylphenol, and 4- $n$-propylphenol exerted antiandrogenicity. Isobutylparaben, $n$-butylparaben, isopropylparaben, and $n$-propylparaben also had antiandrogenic activity. The level at which these parabens effects were observed is a value that is lower than the upper limit of the acceptable daily intake (ADI, $10 \mathrm{mg} / \mathrm{kg} / \mathrm{day}$ ). 4-Ethylphenol, 4methylphenol, ethylparaben, and methylparaben had no effect on the androgen-responsive luciferase activity. We propose that the AR-EcoScreen system is suitable for a battery of titer-1 tests to identify chemicals that affect the endocrine system, and that the ADI value of total parabens may have to be lowered in Japan.
\end{abstract}

Key words — antiandrogen, alkylphenol, paraben, androgen receptor, AR-EcoScreen, endocrine disrupter

\section{INTRODUCTION}

Recently, several studies have shown that some chemicals that are released into the environment without direct toxicologic risks have the ability to disrupt the development and function of endocrine systems of wild animals and humans. ${ }^{1)}$ These socalled endocrine-disrupting chemicals (EDCs) disturb normal endocrine feedback mechanisms either by mimicking a hormone, ${ }^{2)}$ or by blocking hormonal

\footnotetext{
*To whom correspondence should be addressed: Department of Environmental Health, Tokyo Metropolitan Institute of Public Health, 24-1 Hyakunincho 3-chome, Shinjuku-ku, Tokyo 1690073, Japan. Tel.: +81-3-3363-3231; Fax: +81-3-3363-3486; Email: Kanako_Satou@member.metro.tokyo.jp
}

effects. Synthetic and natural chemical substances may have disrupting effects acting as estrogens, antiestrogens, antiandrogens, and thyroactive agents. ${ }^{1)}$ The outcomes on male reproductive health include sperm counts and semen quality, testicular cancer, sex ratio at birth, hypostasis, and undescended testes. Recent studies have identified antiandrogenic activity in environmental chemicals such as vinclozolin, ${ }^{3)}$ and $1,1^{\prime}$-(dichloroethylidene)bis[4chlorobenzene] $\left(p, p^{\prime}\right.$-DDE) ${ }^{2,4,5)}$ It has been hypothesized that increased exposure to environmental endocrine disrupters during fetal or early postnatal life may affect the development of the male reproductive tract through estrogenic or antiandrogenic mechanisms. ${ }^{6-8)}$ Although estrogen is critical for the masculinization of many behaviors in the rat, some 
chemicals are organized specifically by androgens.

The US Environmental Protection Agency (EPA) has proposed that in vitro assays for estrogen receptor (ER)- and androgen receptor (AR)-mediated actions are included in a tier- 1 screening battery to detect hormonally active chemicals (EPA, 1998). Tier-1 screening systems, for example, those using yeast cells, have serious drawbacks, such as the poor transport of many substances across the cell wall and membrane (Interagency Coordinating Committee on the Validation of Alternative Method, 2003). In contrast, a system measuring endocrine reporter-mediated transcription in a stable cell line is more likely to have high sensitivity and specificity so that agonistic and antagonistic actions can be distinguished. We have reported the AR-reporter gene assay using two different types of stably transfected Chinese hamster ovary $(\mathrm{CHO})$ cells $(\mathrm{CHO}-\mathrm{K} 1$ cells do not metabolize steroid hormones and do not express endogenous steroid hormone receptors), AREcoScreen, which expresses androgen-inducible luciferase, and c-luc, which expresses it without the need for hormonal induction. ${ }^{9,10)}$ This method enabled us to detect simultaneously the hormonal effects and cell toxicity of the test chemicals. This reporter gene assay is useful for high-throughput screening of androgen agonists and antagonists because of the high reproducibility and sensitivity. Wilson et al. ${ }^{11)}$ reported that the MDA-kb2 stable cell line is an efficient and accurate tool for the determination of androgen agonists and antagonists and, as such, fills the need for an effective screening tool. MDA-kb2 cells are derived from MDA-MD453 human breast cancer cells, which stably express luciferase through both the AR and glucocorticoid receptor (GR). ${ }^{11)}$ We examined the effects of chemicals using the AR-EcoScreen system and MDA-kb2 cells.

4-Nonylphenol (NP) and 4-octylphenol (OP) are used as antioxidants or stabilizers in plastics and were detected in food packaged with plastic wrapping material. Furthermore, these chemicals are materials for the formation of nonionic detergents such as nonylphenol ethoxylate (NPEO) and octylphenol ethoxylate (OPEO). NPEO and OPEO are used for industrial and domestic cleaning, textile and leather processes, metal working, and cosmetics. Also, each alkylphenolethoxylate is decomposed to the corresponding alkylphenol in the environment. In Japan, NP and OP were produced in amounts of about 16500 and $10000 \mathrm{t}$ in 2000, respectively. Evidence that NP and OP have estrogen- like activity in the study of fish and mammalians has accumulated. ${ }^{12-16)}$ The Ministry of the Environment, Government of Japan, confirmed that NP and OP were endocrine disrupters in 2001 and 2002, respectively. We previously reported that NP and OP bind not only to ER but also to AR, ${ }^{17,18)}$ and OP had slight antiandrogen activity. ${ }^{19)}$

Parabens are widely used as preservatives or stabilizers in food, cosmetics, and medicines. The acceptable daily intake (ADI) prescribed by the Joint FAO/WHO Food Standard Program for parabens is $0-10 \mathrm{mg} / \mathrm{kg} /$ day. Some parabens were reported to have estrogenic activity in vitro. ${ }^{20-23)}$ Subsequently, it was reported that adverse effects occurred in the reproductive system of male rats and mice fed with food containing butyl- and propyl-parabens at a dose lower than or at the same level as the ADI. ${ }^{24-26)}$

The androgenicities of alkylphenols and parabens in in vitro assays have not been systematically reported. In this report, we examined the androgenic or antiandrogenic effects of some alkylphenols and parabens using the AR-EcoScreen system, and these results were compared with those using MDA-kb2 cells.

\section{MATERIALS AND METHODS}

Reagents — The chemicals were used of the highest grade commercially available or used for environmental analysis. The source, purity, and abbreviations of the alkylphenols and parabens are listed in Tables 1 and 2, respectively. Testosterone, dexamethasone (DEX), and cyproterone acetate (CTA) were purchased from Sigma (St. Louis, MO, U.S.A.). $5 \alpha$-Dihydrotestosterone (DHT), 1,1'-(2,2,2trichloroethylidene)bis[4-chlorobezene] ( $p, p^{\prime}$-DDT), 1,1,1-trichloro-2-( $p$-chlorophenyl)-2-(o-chlorophenyl)ethane $\left(o, p^{\prime}\right.$-DDT), $p, p^{\prime}$-DDE, $1,1^{\prime}-(2,2-$ dichloroethylidene)bis[4-chlorobenzene] ( $p, p^{\prime}$ DDD), and the luciferase reagent Pica Gene (LT 2.0 HS), were purchased from Wako Pure Chemical Industries. (Osaka, Japan). Hydroxyflutamide (OHF) was purchased from Tront Research Chemicals (NY, Canada). These chemicals were dissolved in dimethyl sulfoxide (DMSO) for the luciferase reporter gene assay and competitive binding assay.

\section{Reporter Gene Assay with the AR-EcoScreen} System — The AR-reporter gene assay was carried out using two different types of stably transfected CHO-K1 cells, the AR-EcoScreen and c-luc. These cell lines (AR-EcoScreen system) were 
Table 1. Data on Alkylphenols

\begin{tabular}{|c|c|c|c|c|c|}
\hline & Chemical & Abbreviation & $\mathrm{R}$ & Supplier & Purity (\%) \\
\hline & 4-n-Dodecylphenol & DP & $\mathrm{n}-\mathrm{C}_{12} \mathrm{H}_{25^{-}}$ & Kanto Chemical & $70-80$ \\
\hline & 4-n-Nonylphenol & NP & $n-\mathrm{C}_{9} \mathrm{H}_{19^{-}}$ & Kanto Chemical & 99.5 \\
\hline & 4-t-Octylphenol & $t$-OP & $\left(\mathrm{CH}_{3}\right)_{3} \mathrm{CCH}_{2} \mathrm{C}\left(\mathrm{CH}_{3}\right)_{2-}$ & Tokyo Kasei & $>93$ \\
\hline & $n$-Octylphenol & OP & $\mathrm{n}-\mathrm{C}_{8} \mathrm{H}_{17^{-}}$ & Kanto Chemical & 98.6 \\
\hline $\mathrm{OH}$ & 4-n-Hexylphenol & $\mathrm{HP}$ & $n-C_{6} \mathrm{H}_{13^{-}}$ & Kanto Chemical & 99.6 \\
\hline & 4-n-Pentylphenol & $\mathrm{PeP}$ & $n-C_{5} \mathrm{H}_{11^{-}}$ & Kanto Chemical & 99.0 \\
\hline & 4-n-Propylphenol & PrP & $\mathrm{n}-\mathrm{C}_{3} \mathrm{H}_{7}-$ & Kanto Chemical & 98.6 \\
\hline & 4-Ethylphenol & EP & $\mathrm{C}_{2} \mathrm{H}_{5}^{-}$ & Kanto Chemical & $>97.0$ \\
\hline & 4-Methylphenol & MP & $\mathrm{CH}_{3-}^{-}$ & Tokyo Kasei & $>99$ \\
\hline
\end{tabular}

Table 2. Data on Alkyl Parahydroxybenzoate (Parabens)

\begin{tabular}{|c|c|c|c|c|c|}
\hline \multirow{4}{*}{$\stackrel{\mathrm{O}}{\mathrm{C}}-\mathrm{O}-\mathrm{R}$} & Chemical & Abbreviation & $\mathrm{R}$ & Supplier & Purity (\%) \\
\hline & $\begin{array}{l}\text { Isobutyl } p \text {-hydroxybenzoate } \\
\text { (Isobutyl paraben) }\end{array}$ & PB-iBu & $-\mathrm{CH}_{2} \mathrm{CH}\left(\mathrm{CH}_{3}\right)_{2}$ & Tokyo Kasei & $>99.0$ \\
\hline & $\begin{array}{l}\text { Butyl } p \text {-hydroxybenzoate } \\
\text { (Butyl paraben) }\end{array}$ & PB-nBu & $-\left(\mathrm{CH}_{2}\right)_{3} \mathrm{CH}_{3}$ & Tokyo Kasei & $>99.0$ \\
\hline & $\begin{array}{l}\text { Isopropyl } p \text {-hydroxybenzoate } \\
\text { (Isopropyl paraben) }\end{array}$ & PB-iPr & $-\mathrm{CH}\left(\mathrm{CH}_{3}\right)_{2}$ & Tokyo Kasei & $>99.0$ \\
\hline & $\begin{array}{l}\text { Propyl } p \text {-hydroxybenzoate } \\
\text { (Propyl paraben) }\end{array}$ & PB-nPr & $-\left(\mathrm{CH}_{2}\right)_{2} \mathrm{CH}_{3}$ & Tokyo Kasei & $>99.0$ \\
\hline & $\begin{array}{l}\text { Ethyl } p \text {-hydroxybenzoate } \\
\text { (Ethyl paraben) }\end{array}$ & PB-Et & $-\mathrm{C}_{2} \mathrm{H}_{5}$ & Tokyo Kasei & $>99.0$ \\
\hline & $\begin{array}{l}\text { Methyl } p \text {-hydroxybenzoate } \\
\text { (Methyl paraben) }\end{array}$ & PB-Me & $-\mathrm{CH}_{3}$ & Tokyo Kasei & $>99.0$ \\
\hline
\end{tabular}

provided by Otsuka Pharmaceutical Co. Ltd. (Tokushima, Japan). AR-EcoScreen cells are derived from a CHO cell line that is stably transformed with a plasmid containing an androgen receptor-response element (derived from the rat prostate $\mathrm{C} 3$ gene) fused to a luciferase gene, and plasmid encoding the androgen receptor cDNA sequence. ${ }^{9,10)} \mathrm{c}$-luc Cells are luciferase genes stably transfected into $\mathrm{CHO}-\mathrm{K} 1$ cells and stably expressed luciferase without the need for androgen induction. ${ }^{9,10)}$

The AR-EcoScreen was maintained in Dulbecco's modified Eagle's medium (DMEM)/F12 (Gibco BRL, Invitrogen, CA, U.S.A.) supplemented with penicillin $100 \mathrm{U} / \mathrm{ml}$, streptomycin $100 \mu \mathrm{g} / \mathrm{ml}$, zeocin $200 \mu \mathrm{g} / \mathrm{ml}$, hygromycin $200 \mu \mathrm{g} / \mathrm{ml}$, and $10 \%$ fetal bovine serum (FBS) at $37^{\circ} \mathrm{C}$ under a humidified atmosphere of $5 \% \mathrm{CO}_{2} /$ air. 1st day: For the experiments, the cells were trypsinized and prepared at a density of $1.1 \times 10^{5} \mathrm{cell} / \mathrm{s} / \mathrm{ml}$ in phenol red free DMEM/F12 containing 5\% charcoal-dextran treated FBS (CDFBS, Hyclone, Logan, UT, U.S.A.), and then seeded at $90 \mu \mathrm{l}$ of culture medium/well in 96well white clear-bottomed plates (\#3610, Corning,
NY, U.S.A.) and incubated for $24 \mathrm{hr}$ at $37^{\circ} \mathrm{C}$. 2nd day: After $24 \mathrm{hr}$ culture, various concentrations of chemicals dissolved in 1\% DMSO (10 $\mu \mathrm{l})$ were added to each well in the absence of DHT for the agonist or in the presence of DHT $\left(1.7 \times 10^{-10} \mathrm{M}\right)$ for the antagonist detection assays. The final concentration of DMSO was $0.1 \%$ in the medium. 3rd day: Following 16-24 hr of culture, $100 \mu \mathrm{l}$ of Pica Gene was added to each well. After shaking the plate at room temperature for $5 \mathrm{~min}$, the chemiluminescence intensity was measured with a microplateluminometer (Berthold, LB 96V), and the luciferase activity was determined.

The measurement of cell toxicity was carried out using c-luc. The maintenance of c-luc, reaction with the chemicals, and detection of luciferase activity were carried out using a method similar to that for AR-EcoScreen. We also determined the cell toxicity of chemicals for AR-EcoScreen. After the reactions of AR-EcoScreen and the various chemicals, the cells were fixed with $10 \%$ tricloroacetic acid and stained them with sulfordamine-B (SRB, Kanto Chemical, Tokyo, Japan) (SRB method). ${ }^{27,28)}$ The de- 

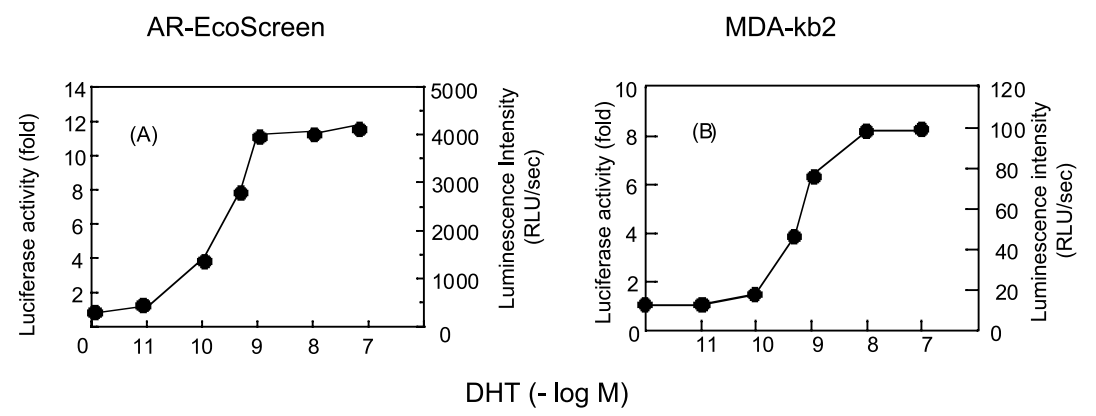

Fig. 1. Response of AR-EcoScreen and MDA-kb2 to DHT

AR-EcoScreen (A) and MDA-kb2 (B) were treated with various concentrations of DHT, and the luminescence intensity of each cell was measured. Right axes in both figures show actual luminescence intensity (luciferase activity), and left axes present the fold induction, which was the ratio of the luciferase activity in the presence of DHT to that in the vehicle control. The luciferase activity in $0.1 \%$ DMSO was the same as in the absence of DMSO. The S.D. was less than $2.5 \%(n=6)$.

veloped color was read at $492 \mathrm{~nm}$ on a microtiter spectrophotometer. Alternatively, the ATP contents in these cells were measured using a luminescent viability assay kit (Promega, Wisconsin, U.S.A.) after the reaction (ATP method).

\section{Reporter Gene Assay with MDA-kb2 — The} MDA-kb2 cell line was kindly provided by V. S. Wilson (Reproductive Toxicology Division, US EPA, and Research Triangle Park, NC, U.S.A.). The assay using this cell line was carried out essentially according to the method of Wilson et al. ${ }^{11)}$ Briefly, the MDA-kb2 cell line was maintained in L-15 media (Gibco BRL) supplemented with penicillin $100 \mathrm{U} / \mathrm{ml}$, streptomycin $100 \mu \mathrm{g} / \mathrm{ml}$, amphotericin B $0.25 \mu \mathrm{g} / \mathrm{ml}$ and $10 \% \mathrm{CDFBS}$ at $37^{\circ} \mathrm{C}$ under a humidified atmosphere, without $\mathrm{CO}_{2}$. 1st day: For the experiments, the cells were trypsinized and prepared at a density of $1.1 \times 10^{5}$ cells $/ \mathrm{ml}$ in the medium, and then seeded at $90 \mu \mathrm{l}$ of culture medium/well in 96well white clear-bottomed plates (\#3610, Corning) and incubated for $4-6 \mathrm{hr}$ at $37^{\circ} \mathrm{C}$. When the cells were attached, the medium was removed and various concentrations of chemicals dissolved in $1 \%$ DMSO $(10 \mu \mathrm{l})$ were added to each well in the absence of DHT for the agonist or in the presence of DHT $\left(6.0 \times 10^{-10} \mathrm{M}\right)$ for the antagonist detection assay. The final concentration of DMSO was $0.1 \%$ in the reaction medium. 2nd day: After overnight culture, the culture medium was removed by aspirating, and then $100 \mu \mathrm{l}$ of Pica Gene was added to each well. After shaking the plate at room temperature for $30 \mathrm{~min}$, the chemiluminescence intensity was measured.

To evaluate cell toxicity, reactions between MDA-kb2 and the various chemicals were carried out using the SRB and ATP methods like those for the reporter gene assay with the AR-EcoScreen.

Competitive Binding Assays for AR — The competitive binding assay for AR was carried out according to the method previously reported. ${ }^{17)}$ The assay was determined using a Ligand Screening System-Androgen Receptor kit (Toyobo Co., Ltd., Osaka, Japan).

\section{RESULTS}

\section{Response to Known Androgens DHT and Test- osterone}

After culturing in the presence of various concentrations of DHT, the luciferase activities of AREcoScreen and MDA-kb2 were determined with Pica Gene following the removal of the culture media. The right vertical scales in both Fig. 1A and 1B show the actual luminescence intensity (luciferase activity), and the left express the ratio of the luciferase activity in the presence of DHT to that in the vehicle control (0.1\% DMSO). The activity of AREcoScreen significantly increased at $1.0 \times 10^{-11} \mathrm{M}$, and reached almost the maximal level, which was about 12 -fold that of the vehicle control. The 50\% effective concentration $\left(\mathrm{EC}_{50}\right.$ value, the concentration required for half-maximal activation of luciferase) was $1.7 \times 10^{-10} \mathrm{M}$. The activity of MDA$\mathrm{kb} 2$ was also increased by DHT, and the $\mathrm{EC}_{50}$ value was $6.0 \times 10^{-10} \mathrm{M}$. However, the actual luciferase activity of AR-EcoScreen was extremely high compared with that of MDA-kb2.

When Pica Gene was added to the wells immediately after culturing the AR-EcoScreen in the test chemicals for $24 \mathrm{hr}$, the intensity of chemiluminescence was decreased to about $30 \%$ of the intensity 
AR-EcoScreen

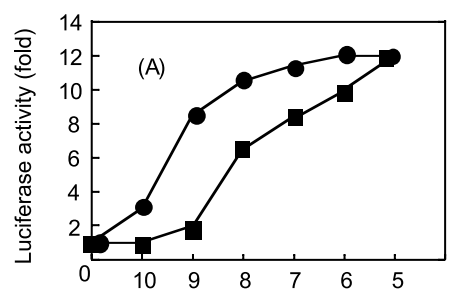

MDA-kb2

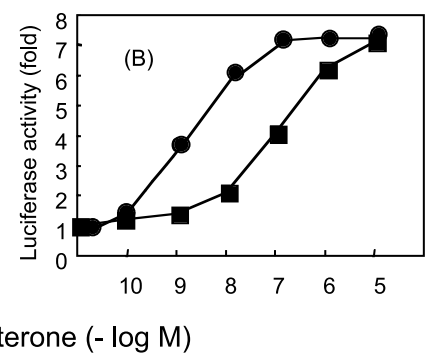

Fig. 2. Response of AR-EcoScreen and MDA-kb2 to Testosterone

AR-EcoScreen (A) and MDA-kb2 (B) were treated with various concentrations of testosterone in the presence $10^{-6} \mathrm{M}$. The vertical axes show the luciferase activity. The S.D. was less than $1.9 \%(n=6)$.

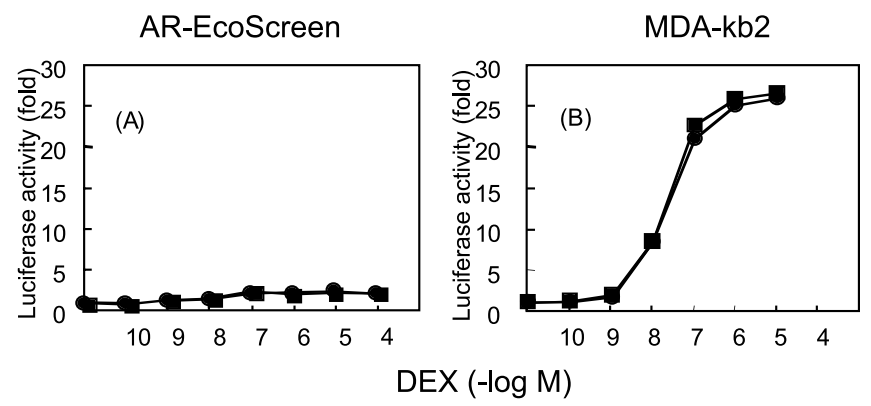

Fig. 3. Response of AR-EcoScreen and MDA-kb2 to DEX

AR-EcoScreen (A) and MDA-kb2 (B) were treated with various concentrations of DEX in the presence (匹) or absence (-) of OHF $1.0 \times 10^{-6} \mathrm{M}$. Vertical axes show the luciferase activity. The S.D. was less than $1.8 \%(n=6)$.

after eliminating the culture medium, but the fold induction was the same regardless of whether the culture medium was removed. Therefore we measured the luciferase activity without eliminating the AR-EcoScreen's culture medium. As for MDA-kb2 cells, the intensity of chemiluminescence was decreased so that it was not possible to measure it. Accordingly, Pica Gene was added to the wells after eliminating the MDA-kb2 culture medium.

Testosterone also induced the luciferase activities of both cells in a concentration-dependent manner (Fig. 2A and 2B). The $\mathrm{EC}_{50}$ value was $4.0 \times 10^{-10}$ with AR-EcoScreen. OHF $\left(1.0 \times 10^{-6} \mathrm{M}\right)$, an ARantagonist, reduced the induction of luciferase activity by testosterone, and the $\mathrm{EC}_{50}$ value was $1.0 \times$ $10^{-8} \mathrm{M}$. However, the maximum activity was the same in both the presence and absence of OHF. On MDA-kb2, the $\mathrm{EC}_{50}$ values were $1.2 \times 10^{-7}$ and 1.3 $\times 10^{-9} \mathrm{M}$ in the presence and absence of OHF, respectively.

\section{Response to the Known GR Agonist DEX}

The luciferase activity of AR-EcoScreen showed little effect due to DEX, which is a GR agonist (Fig. 3A). On the other hand, the activity of MDA$\mathrm{kb} 2$ was increased by DEX in a concentration-dependent manner from $10^{-9}$ to $10^{-6} \mathrm{M}$, and the maximum activity (more than 25 -fold induction) was obtained at DEX $1.0 \times 10^{-6} \mathrm{M}$ (Fig. 3B). OHF did not affect the DEX-inducing activity.

\section{Response to Known AR Antagonists CTA, OHF, and DDT and Related Compounds}

The response of AR-EcoScreen and c-luc to antiandrogens was examined (Fig. 4). The AR antagonists CTA and OHF were coadministered with DHT $1.7 \times 10^{-10} \mathrm{M}$, which produces $50 \%$ of the maximal AR-mediated signal, in the media. The luciferase activity in the presence of DHT alone was expressed as 1.0-fold. The DHT-induced luciferase activity of AR-EcoScreen was decreased by CTA. The half-maximal inhibition value $\left(\mathrm{IC}_{50}\right)$ was $3.0 \times$ $10^{-7} \mathrm{M}$, though that of c-luc, which stably expresses luciferase without the need for induction, was not affected. OHF also decreased the DHT-induced luciferase activity of AR-EcoScreen, and the $\mathrm{IC}_{50}$ value 

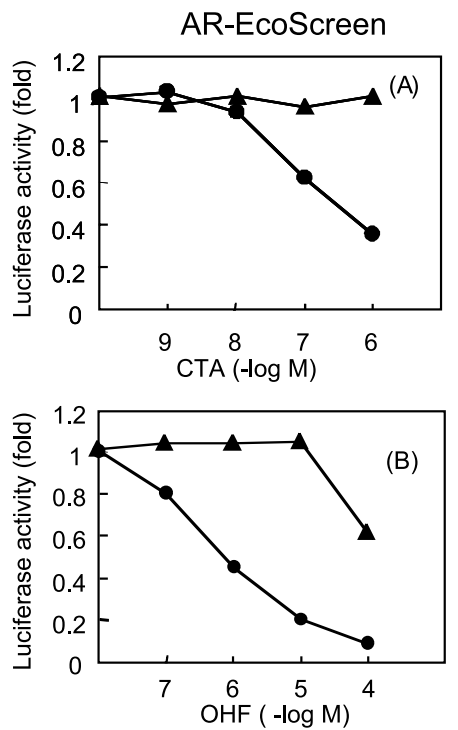

Fig. 4. Response of the AR-EcoScreen System (AR-EcoScreen and c-luc) to Androgen Antagonists, CTA and OHF

AR-EcoScreen $(\bullet)$ and c-luc $(\boldsymbol{\Lambda})$ were treated, respectively, with various concentrations of CTA (A) or OHF (B) in the presence of DHT $1.7 \times 10^{-10} \mathrm{M}$. Luciferase activity in the presence of DHT alone is shown as 1.0-fold. The S.D. was less than $1.6 \%(n=6)$.

was $7.0 \times 10^{-7} \mathrm{M}$. The luciferase activity of c-luc was not decreased at OHF $7.0 \times 10^{-7} \mathrm{M}$ and was only $40 \%$ at a high concentration of $\mathrm{OHF}\left(1.0 \times 10^{-4} \mathrm{M}\right)$. The antagonist activity of OHF was detected with the AR-EcoScreen system. The cytotoxicity of chemicals was also examined by measuring the content of intracellular ATP (ATP method) or the amount of protein fixed on microplates (SRB method). These results corresponded to those determined based on the cell proliferation rate of c-luc (data not shown). It was clarified that the cytotoxicity could be measured using c-luc.

With MDA-kb2, the DHT $\left(6.0 \times 10^{-10} \mathrm{M}\right.$, which produces $50 \%$ of the maximal AR-mediated signal)induced activity was reduced by CTA, but an $\mathrm{IC}_{50}$ value was not obtained (Fig. 5A). Cell death was not caused by CTA at $1.0 \times 10^{-6} \mathrm{M}$ or less. OHF also decreased the luciferase activity, and the $\mathrm{IC}_{50}$ value was $2.4 \times 10^{-5} \mathrm{M}$. Cell death began to occur at more than $1.0 \times 10^{-5} \mathrm{M}$ OHF (Fig. 5B).

The antagonistic activity of $p, p^{\prime}$-DDT, $o, p^{\prime}$-DDT, $p, p^{\prime}$-DDE, and $p, p^{\prime}$-DDD were examined using the AR-EcoScreen system (Fig. 6). $p, p^{\prime}$-DDT, $o, p^{\prime}$-DDT, $p, p^{\prime}$-DDE, and $p, p^{\prime}$-DDD decreased the DHT-induced luciferase activity concentration dependently, with $\mathrm{IC}_{50}$ values of $3.2 \times 10^{-5}, 3.2 \times 10^{-5}, 3.0 \times 10^{-5}$, and $3.3 \times 10^{-5} \mathrm{M}$, respectively. The effects on the luciferase activity of c-luc were also examined. The
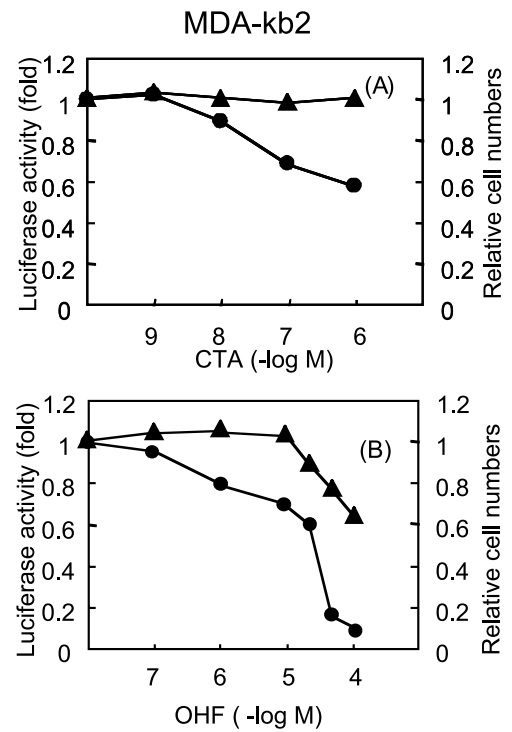

Fig. 5. Response of MDA-kb2 to Androgen Antagonists, CTA, and $\mathrm{OHF}$

MDA-kb2 was treated with various concentrations of CTA or OHF in the presence of DHT $6.0 \times 10^{-10} \mathrm{M}$. The luciferase activity $(-)$ and relative cell numbers $(\mathbf{\Lambda})$ in the presence of DHT alone are shown as 1.0-fold. The S.D. was less than $1.9 \%(n=6)$.

activity was only slightly decreased and only by high concentrations of $o, p^{\prime}$-DDT, $p, p^{\prime}$-DDE and $p, p^{\prime}$ DDD, except for the obvious decrease due to $p, p^{\prime}-$ DDT, which has cell toxicity.

\section{AR Antagonist Activity of Alkylphenols}

We studied the androgenic and antiandrogenic activities of alkylphenols using the AR-EcoScreen system (Table 3 and Fig. 7A-7G). All tested alkylphenols had no AR agonist activity, because they had no increasing effect on the luciferase activity of AR-EcoScreen. In the assay of AR antagonist activity of alkylphenols, various concentrations of each alkylphenol were coadministered with DHT in the AR-EcoScreen and c-luc medium. The DHTinduced luciferase activity of AR-EcoScreen was decreased with 4- $n$-dodecylphenol (DP) in a concentration dependently, and the $\mathrm{IC}_{50}$ value was low at $6.0 \times 10^{-6} \mathrm{M}$. On the other hand, the luciferase activity of c-luc was not affected by DP $2 \times 10^{-5} \mathrm{M}$ or less, but was decreased to 60 and $35 \%$ at $5.0 \times$ $10^{-5}$ and $1.0 \times 10^{-4} \mathrm{M} \mathrm{DP}$, respectively. The cell toxicity of DP was relatively weak. These results suggest that DP has high AR antagonist activity. NP and 4- $t$-octylphenol ( $t$-OP) also inhibited the DHT-induced luciferase activity of AR-EcoScreen, and the $\mathrm{IC}_{50}$ values were $9.0 \times 10^{-6}$ and $2.2 \times 10^{-6} \mathrm{M}$, respectively. The luciferase activity of c-luc was not af- 


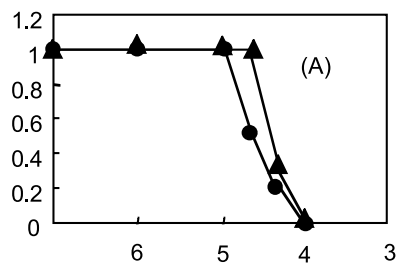

$p, p^{\prime}-\mathrm{DDT}(-\log \mathrm{M})$
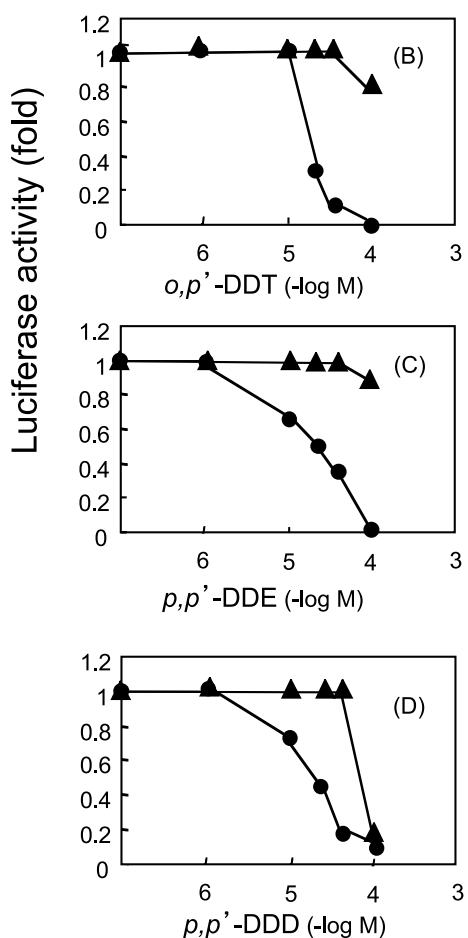

Fig. 6. AR Antagonist Assay of DDT and Related Compounds with the AR-EcoScreen System

AR-EcoScreen and c-luc were treated, respectively, with various concentrations of DDT or related compounds in the presence of DHT $1.7 \times 10^{-10} \mathrm{M}$. The luciferase activity in the presence of DHT alone is shown as 1.0 -fold. A, $p, p^{\prime}$-DDT; B, $o, p^{\prime}$-DDT; C, $p, p^{\prime}$-DDE; D, $p, p^{\prime}$ DDD. The S.D. was less than $1.6 \%(n=6)$.

fected by NP $2.0 \times 10^{-5} \mathrm{M}$ or less, or $t$-OP $1 \times 10^{-5} \mathrm{M}$ or less, and was only decreased at a high concentration. These compounds apprared to be AR antagonists and to have relatively low cell toxicity. OP, 4$n$-hexylphenol (HP), 4-n-pentylphenol (PeP), and 4$n$-propylphenol (PrP) reduced the DHT-induced luciferase activity of AR-EcoScreen, and the $\mathrm{IC}_{50}$ values were $4.6 \times 10^{-5}, 2.0 \times 10^{-5}, 2.4 \times 10^{-5}$, and $6.6 \times$ $10^{-5} \mathrm{M}$, respectively. They had relatively weak inhibitory effects on the luciferase activity of c-luc. These compounds also have AR antagonist activity. MP and EP $1.0 \times 10^{-4} \mathrm{M}$ did not affect the luciferase activities of either AR-EcoScreen or c-luc (Table 3).

The effects of alkylphenols on the DHT-induced luciferase activity and the cell viability of MDAkb2 are shown in Fig. 8A-8G. The DHT-induced luciferase activity was decreased by alkylphenols at a relatively high concentration. However, they also exerted cell toxicity toward MDA-kb2 at the same concentrations that resulted in a decrease in the activity. We were unable to clarify the AR antagonist activity of the alkylphenols.

\section{AR Antagonist Activity of Parabens}

We studied on the AR agonist and antagonist activities of parabens using the AR-EcoScreen system (Fig. 9 and Table 3). No AR agonist activity of these compounds was observed. On the other hand, isobutyl $p$-hydroxybenzoate $(\mathrm{PB}-\mathrm{iBu})$, butyl $p$ hydroxybenzoate (PB-nBu), isopropyl $p$-hydroxybenzoate (PB-iPr), and propyl $p$-hydroxybenzoate (PB-nPr) inhibited the DHT-induced luciferase activity. The $\mathrm{IC}_{50}$ values were $7.6 \times 10^{-5}, 6.8 \times 10^{-5}$, $4.2 \times 10^{-5}$ and $8.6 \times 10^{-5} \mathrm{M}$, respectively. These compounds had no effect on the luciferase activity of cluc. They were suggested to have AR antagonist activity, although the activity was not very high. ethyl $p$-hydroxybenzoate (PB-Et) and methyl $p$-hydroxybenzoate (PB-Me) hardly affected the luciferase activities either AR-EcoScreen or c-luc.

\section{Binding Affinity of Alkylphenols and Parabens to $\mathbf{A R}$}

Various doses of alkylphenols and parabens were reacted with human AR in the presence of testosterone. The $\mathrm{IC}_{50}$ values for $\mathrm{AR}$ (concentration of chemical required to reduce the specific testosterone binding by 50\%) are listed in Table 3.

DP and NP had the most potent binding affinity for $\mathrm{AR}$ among the alkylphenols tested, and the $\mathrm{IC}_{50}$ values were the same $\left(1.3 \times 10^{-5} \mathrm{M}\right)$. The AR-binding affinity of $t$-OP was the second strongest, and the $\mathrm{IC}_{50}$ value was $7.4 \times 10^{-5} \mathrm{M}$. OP did not completely inhibit the testosterone binding to AR, and only about $48 \%$ inhibition was obtained at $1.9 \times$ $10^{-4} \mathrm{M}$. HP, PeP, PrP, EP, and MP $1.9 \times 10^{-4} \mathrm{M}$ bound to AR weakly. EP and MP did not bind to AR.

We also examined the AR-binding affinity of parabens. PB-iBu, PB-nBu, PB-iPr, and PB-nPr partially inhibited the testosterone binding, and the inhibition percentages were about $40 \%$ at $1.9 \times 10^{-4} \mathrm{M}$. PB-Et and PB-Me had no AR-binding affinity.

\section{DISCUSSION}

We carried out an AR-reporter gene assay of chemicals using AR-EcoScreen system (AR- 
Table 3. Androgen-Disruptive Effects of Alkylphenols and Parabens

\begin{tabular}{|c|c|c|c|}
\hline \multirow[t]{2}{*}{ Chemical } & \multicolumn{2}{|c|}{ Reporter gene assay with AR-EcoScreen } & \multirow{2}{*}{$\begin{array}{c}\text { AR-binding assay } \\
\mathrm{IC}_{50}{ }^{c}(\mathrm{M})\end{array}$} \\
\hline & $\begin{array}{l}\text { Agonist activity } \\
\left.\mathrm{EC}_{50}{ }^{a}\right)(\mathrm{M})\end{array}$ & $\begin{array}{l}\text { Antagonist activity } \\
\mathrm{IC}_{50}{ }^{b)}(\mathrm{M})\end{array}$ & \\
\hline DP & $\mathrm{NE}$ & $6.0 \times 10^{-6}$ & $1.3 \times 10^{-5}$ \\
\hline NP & $\mathrm{NE}$ & $9.0 \times 10^{-6}$ & $1.3 \times 10^{-5}$ \\
\hline$t$-OP & $\mathrm{NE}$ & $2.2 \times 10^{-6}$ & $7.4 \times 10^{-5}$ \\
\hline OP & $\mathrm{NE}$ & $4.6 \times 10^{-5}$ & $>1.9 \times 10^{-4 e)}$ \\
\hline HP & $\mathrm{NE}$ & $2.0 \times 10^{-5}$ & $>1.9 \times 10^{-4 f)}$ \\
\hline $\mathrm{PeP}$ & $\mathrm{NE}$ & $2.4 \times 10^{-5}$ & $>1.9 \times 10^{-4 f)}$ \\
\hline $\operatorname{PrP}$ & $\mathrm{NE}$ & $6.6 \times 10^{-5}$ & $>1.9 \times 10^{-4 f)}$ \\
\hline $\mathrm{EP}$ & $\mathrm{NE}$ & $\mathrm{NE}$ & $\mathrm{NE}$ \\
\hline MP & $\mathrm{NE}$ & $\mathrm{NE}$ & $\mathrm{NE}$ \\
\hline PB-iBu & $\mathrm{NE}$ & $7.6 \times 10^{-5}$ & $\left.>1.9 \times 10^{-4} g\right)$ \\
\hline PB-nBu & $\mathrm{NE}$ & $6.8 \times 10^{-5}$ & $>1.9 \times 10^{-4 g)}$ \\
\hline PB-iPr & $\mathrm{NE}$ & $4.2 \times 10^{-5}$ & $>1.9 \times 10^{-4 g)}$ \\
\hline PB-nPr & $\mathrm{NE}$ & $8.6 \times 10^{-5}$ & $>1.9 \times 10^{-4 g)}$ \\
\hline PB-Et & $\mathrm{NE}$ & $>1.0 \times 10^{-4}$ & $\mathrm{NE}$ \\
\hline PB-Me & $\mathrm{NE}$ & $>1.0 \times 10^{-4}$ & $\mathrm{NE}$ \\
\hline Bisphenol A & $\mathrm{NE}$ & $2.5 \times 10^{-6}$ & $7.9 \times 10^{-6}$ \\
\hline DHT & $1.7 \times 10^{-10}$ & - & - \\
\hline Testosterone & $4.0 \times 10^{-10}$ & - & - \\
\hline Cyproterone acetate & $\mathrm{NE}$ & $3.0 \times 10^{-7}$ & - \\
\hline Hydroxy fulutamide & - & $7.0 \times 10^{-7}$ & - \\
\hline Mibolerone $^{d)}$ & - & - & $1.7 \times 10^{-8}$ \\
\hline $\begin{array}{l}\text { NE: No effect at } 1 . \\
\text { tration of the chemicals } \\
\text { icals required for reduci } \\
\text { Concentration of the ch } \\
\text { androgen, attachment } w \\
\text { testosterone binding at } 1\end{array}$ & $\begin{array}{l}\times 10^{-4} \mathrm{M} \text { (reporter } \\
\text { oducing } 50 \% \text { of max } \\
\mathrm{g} 50 \% \text { of luciferase } \\
\text { nicals required to re } \\
\mathrm{h} \text { Ligand Screening } \\
9 \times 10^{-4} \mathrm{M} \text { chemica }\end{array}$ & $\begin{array}{l}\text { assay) or } 1.9 \times 10^{-4} \mathrm{M} \\
\text { um luciferase activity. } b \\
\text { vity at } 1.7 \times 10^{-10} \mathrm{M} 5 \\
\text { e the specific testosteror } \\
\text { tem-Androgen Recepto } \\
\text { ere } 48,8 \text { and } 40 \% \text {, resp }\end{array}$ & $\begin{array}{l}\text { nding assay). a) Concen- } \\
\text { ntration of the test chem- } \\
\text { Irotestosterone (DHT).c) } \\
\text { ing by } 50 \% . d \text { ) Synthetic } \\
\text { g) Inhibition rates of the } \\
\text {. }\end{array}$ \\
\hline
\end{tabular}

EcoScreen and c-luc cells) or MDA-kb2. ${ }^{11)}$ The luciferase activities of the two reporter gene assays are induced by androgens and the $\mathrm{EC}_{50}$ values for DHT or testosterone in each cell line were almost the same. However, the net luciferase activity was extremely high with the AR-EcoScreen. The expression levels of AR and/or luciferase in the AREcoScreen were higher than those in MDA-kb2. The activity of AR-EcoScreen can be measured more easily than that of MDA-Kb2. Furthermore, it is possible to measure the signal from only the transfected androgen receptor with AR-EcoScreen system. However, MDA-kb2 has a GR in addition to the AR, unlike AR-EcoScreen, and the luciferase of MDA-kb2 is also highly expressed by GR agonists such as corticosterone, aldosterone, and DEX. ${ }^{11)}$ When using MDA-kb2, it is necessary to clarify whether the luciferase activity was induced by the AR agonist or GR agonist. AR-EcoScreen stably expresses human androgen receptor, and inducible expresses the luciferase based reporter gene. C-luc cell stably expresses luciferase without the need for induction and was used to assess the cell toxicity of the test chemicals. AR-EcoScreen system is useful for a high throughput screening of androgen agonists and androgen antagonists, because it is possible to simultaneously detect both the hormonal effects and cell toxicity of the chemicals. The androgen-induced luciferase activity of AR-EcoScreen was about 100 -fold more sensitive to the antagonist than MDA-kb2 when considering the differences in the $\mathrm{IC}_{50}$ values of CTA, OHF, and alkylphenols. This was considered to be because the expression level of AR in AR-EcoScreen is extremely high compared with that in MDA-kb2.

DDT and its metabolites have been reported to have androgen antagonist activity. ${ }^{2,45)}$ It was shown in the reporter gene assay, using the AR-EcoScreen, 
AR-EcoScreen
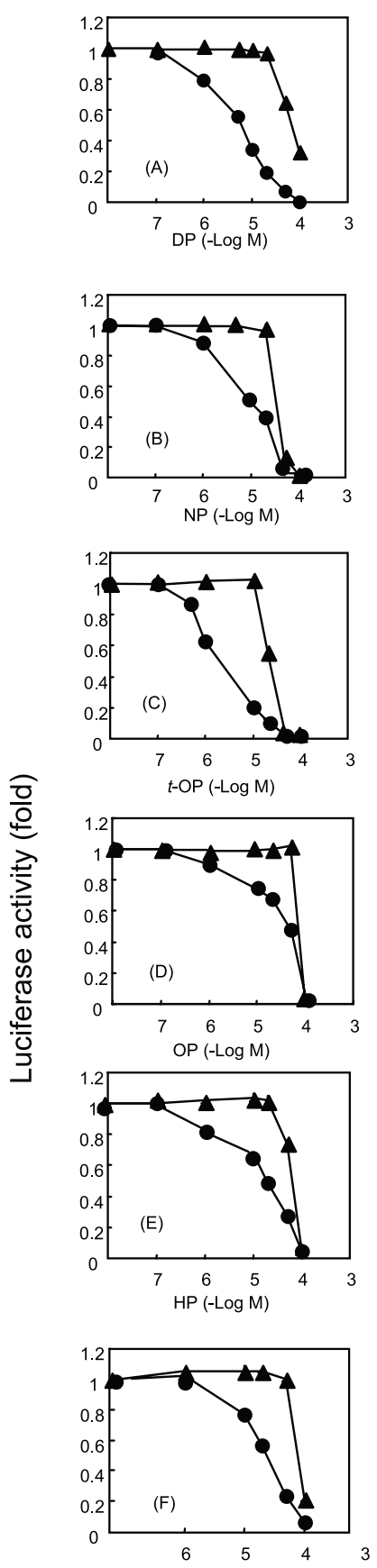

PeP (-Log M)

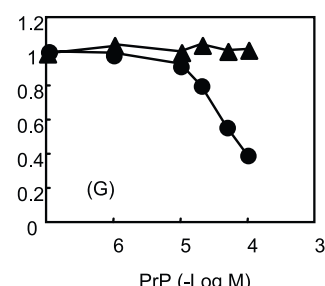

Fig. 7. AR Antagonist Assay of Alkylphenols with AREcoScreen System

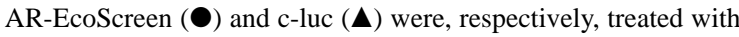
various concentrations of each alkylphenol in the presence of DHT 1.7 $\times 10^{-10}$ M. A, DP; B, NP; C, 4-t-octylphenol (t-OP); D, OP; E, 4-nhexylphenol (HP); F, 4-n-pentylphenol (PeP); G, 4-n-propylphenol (PrP). The S.D. was less than $1.8 \%(n=6)$.
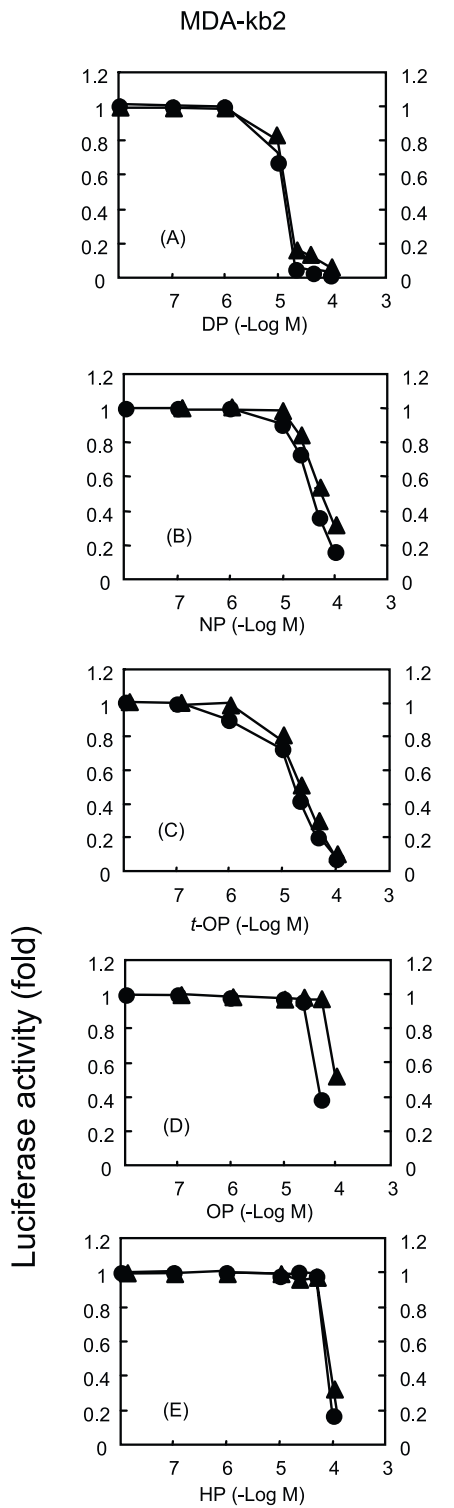

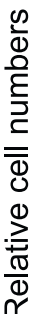
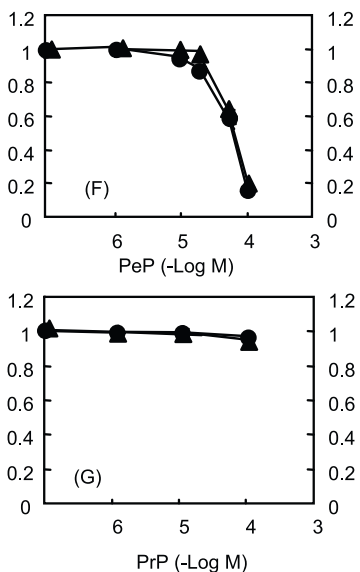

Fig. 8. AR Antagonist Assay of Alkylphenols with MDA-kb2 MDA-kb2 was treated with various concentrations of each alkylphenol in the presence of DHT $6.0 \times 10^{-10} \mathrm{M}$. Left axes show the luciferase activity $(-)$ and the right show the relative cell numbers $(\boldsymbol{\Lambda})$. Chemicals (A-G) are the same as listed in Fig. 7. The S.D. was less than $2.0 \%(n=4)$. 

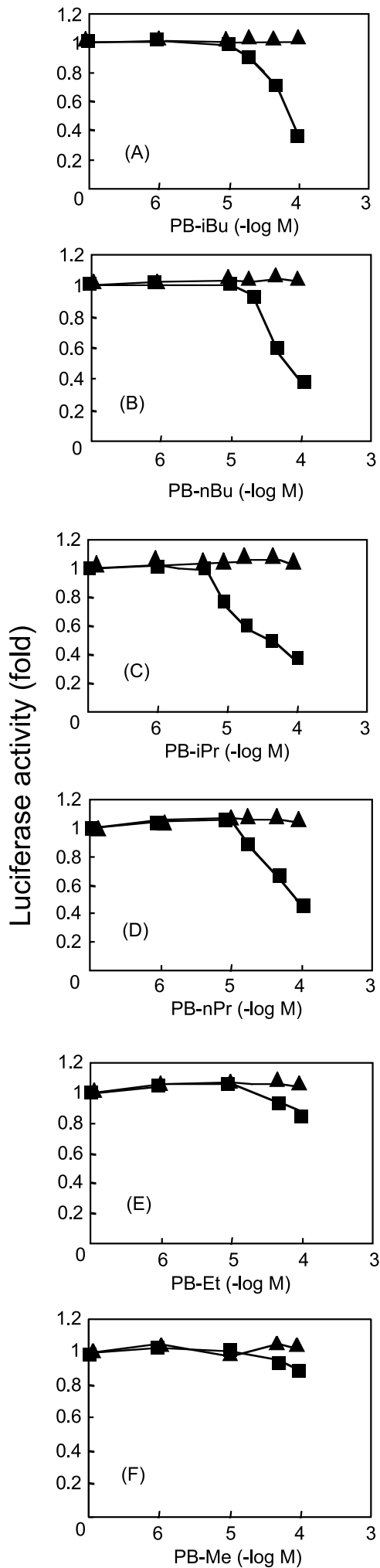

Fig. 9. AR Antagonist Assay of Parabens with the AREcoScreen System

AR-EcoScreen ( $)$ and c-luc ( $\mathbf{\Delta})$ were treated, respectively, with various concentrations of each paraben in the presence of DHT $1.7 \times$ $10^{-10} \mathrm{M}$. A, isobutyl $p$-hydroxybenzoate (PB-iBu); B, butyl $p$ hydroxybenzoate (PB-nBu); C, isopropyl $p$-hydroxybenzoate (PB-iPr); $\mathrm{D}$; propyl $p$-hydroxybenzoate (PB-nPr); E, ethyl $p$-hydroxybenzoate (PBEt); F, methyl $p$-hydroxybenzoate (PB-Me). The S.D. was less than $1.6 \%$ $(n=6)$. that $p, p^{\prime}$-DDT, $o, p^{\prime}$-DDT, $p, p^{\prime}$-DDE, and $p, p^{\prime}$-DDD are androgen antagonists.

The reporter gene assay using the AR-EcoScreen system clarified that alkylphenols such as DP, NP, $t$ OP, OP, HP, PeP, and PrP have androgen antagonist activity. On the other hand, they were not detected by MDA-kb2. This was because the luciferase activity of MDA-kb2 is less sensitive to AR antagonists as described above, and the decreasing DHTinduced luciferase activity and cell death were caused by alkylphenols at about the same concentration. DP, NP, $t$-OP, and OP have a relatively high binding affinity for AR. We considered that the AR antagonist activity of these alkylphenols was caused by the binding to AR. HP, PeP, and PrP also have AR antagonist activity, though they have weak binding affinity for AR. Alkylphenols, such as NP and $\mathrm{OP}$, were detected in the water of many rivers in Japan, Europe, the U.S.A., and other countrie ${ }^{29-33)}$ and they are believed to feminize fish due to their estrogen-like activity. However, our results demonstrated that NP and/or OP may exert AR antagonist activity on fish. There is the possibility that the AR antagonist activity, independently of the ER agonist activity, takes part in the endocrine-disrupting effects of alkylphenols in vivo.

Parabens, which are widely used in food, cosmetics, and medicines, have been reported to exert estrogen-like activity in vitro and in vivo. ${ }^{20-23)}$ In this report, the parabens (PB-iBu, -nBu, -iPr, -nPr) were shown to have $\mathrm{AR}$ antagonist activity and binding affinity for AR. The exposure level at which these effects were observed was lower than the upper limit of the ADI $(10 \mathrm{mg} / \mathrm{kg} /$ day $)$ of parabens (PB-nPr, -Et, $-\mathrm{Me}$ ) in the European Community [Scientific Committee for Food (SCF), 1996]. ${ }^{20)}$ The SCF considered that PB-nPr should not be included in the full group ADI of $0-10 \mathrm{mg} / \mathrm{kg}$ body weight for the sum of PB-Et and PB-Me and their sodium salts in April 2004. PB-nPr, contrary to PB-Et and PB-Me, has effects on sex hormones and the male reproductive organs in juvenile rats. ${ }^{25)}$ Recently, Darbre et al. ${ }^{34)}$ reported that parabens were detected in tissue from human breast tumors, and they suspected the influence of parabens on breast cancer. It is probably necessary to refrain from the use of parabens, and the ADI value $(0-10 \mathrm{mg} / \mathrm{kg}$ body weight for the sum of PB-iBu, -nBu, -iPr, -nPr, and -Et and their sodium salts) may have to be lowered in Japan.

To explore the hypothesis that EDCs might have played a role in the deterioration in the quantity and quality of human semen over the last 50 years, as 
well as in the increased incidence of testicular and prostate cancer and cryptorchidism in males and the incidence of breast cancer in both males and females in the industrialized world, it is necessary to identify putative causal agents by the systematic screening of environmental chemicals and chemicals present in human foods to assess their ability to disrupt the endocrine system. ${ }^{2)}$ Sonnenschein and Soto proposed that it is necessary to develop methods to measure cumulative exposure to estrogen mimics, antiandrogens, and other disruptors. ${ }^{2)}$ In this report, we established that the AR-EcoScreen system is a useful method for examining chemical androgenicity and clarified that some chemicals (alkylphenols and parabens) have both estrogenicity and antiandrogenicity.

\section{REFERENCES}

1) Colborn, T., Vom Sall, F. S. and Soto, A. M. (1993) Developmental effects of endocrine-disrupting chemicals in wildlife and humans. Environ. Health Perspect., 101, 378-384.

2) Sonnennschein, C. and Soto, A. M. (1998) An update review of environmental estrogen and androgen mimics and antagonists. J. Steroid. Biochem. Mol. Biol., 65, 143-150.

3) Hotchkiss, A. K., Ostby, J. S., Vandenbergh, J. G. and Gray, L. E. (2003) An environmental anti-androgen, vinclozolin, alters the organization of play behavior. Physiol. Behav., 79, 151-156.

4) O'Connor, J. C., Frame, S. R. and Ladics, G. S. (2002) Evaluation of a 15-day screening using intact male rats for identifying antiandrogens. Toxicol. Sci., 69, 92-108.

5) Kojima, H., Iida, M., Katsura, E., Kanetoshi, A., Hori, Y. and Kobayashi, K. (2003) Effects of a diphenyl ether-type herbicide, chlornitrofen, and its amino derivative on androgen and estrogen receptor activities. Environ. Health Perspect., 111, 497-502.

6) Carlsen, E., Toppari, J. and Skakkebaek, N. E. (1999) Secular changes in male reproductive health. In $T o$ wards reproductive certainty: fertility and genetics beyond (Jancen, R. and Motrimer, D., Eds.), Parthenon Publishing Group, New York, pp. 257264.

7) Toppari, J., Larsen, J. C., Christiansen, P., Giwercman, A., Grandjean, P., Guillette, L. J., Jégou, B., Jensen, T. K., Jouannet, P., Keiding, N., Leffers, H., McLachlan, J. A., Meyer, O., Müller, J., Meyts, E. R., Scheike, T., Sharpe, R., Sumpter, J. and Skakkebæk, N. E. (1996) Male reproductive health and environmental xenoestrogens. Environ. Health Perspect., 104(Supple. 4), 741-803.

8) Sharp, R. M. and Skakkebaek, N. E. (1993) Are oestrogens involvevd in falling sperm conts and disorders of the male reproductive tract? Lacent, 341, 1292-1395.

9) Satoh, K., Ohyama, K., Aoki, N., Iida, M. and Nagai, F. (2004) Study on anti-androgenic effects of bisphenol A diglycidyl ether (BADGE), bisphenol F diglycidyl ether (BFDGE) and their derivatives using cells stably transfected with human androgen receptor, AR-EcoScreen. Food Chem. Toxicol., 42, 983-993.

10) Araki, N., Ohno, K., Takeyoshi, M. and Iida, M. (2005) Evaluation of a rapid in vitro androgen receptor transcriptional activation assay using ARAcoScreen ${ }^{\mathrm{TM}}$ cells. Toxicol. In Vitro, 19, 335-352.

11) Wilson, V. S., Bobseine, K., Lambright, C. R. and Gray, L. E. (2002) A novel cell line, MDA-kb2, that stable expresses an androgen- and glucocorticoidresponsive receptor for the detection of hormone receptor agonists and antagonists. Toxicol. Sci., 66, 69-81.

12) Soto, A. N., Justicia, H., Wray, J. W. and Sonnenschein, C. (1991) $p$-Nonyl-phenol: an estrogenic xenobiotic released from "modified" polystyrene. Environ. Health Perspect., 92, 167-173.

13) Harries, J. E., Sheahan, D. A., Jobling, S., Matthiessen, P., Neall, P., Sumpter, J. P., Tylor, T. and Zaman, N. (1997) Estrogenic activity in five United Kingdom rivers detected by measurement of vitellogenesis in caged male trout. Environ. Toxicol. Chem., 16, 534-542.

14) Jobling, S., Scheahan, D., Osborne, J. A., Matthiessen, P. and Sumpter, J. P. (1996) Inhibition of testicular growth in rainbow trout (Oncorhynchus mykiss) exposed to estrogenic alkylphenolic chemicals. Environ. Toxicol. Chem., 15, 194-202.

15) Tabata, A., Kamei, T., Magara, Y., Watanabe, N., Miyamoto, N., Ohnishi, Y. and Itoh, M. (2003) Effects of nonylphenol bisphenol A, 17- $\beta$ estradiol, and their mixture on induction of serum vitellogenin in Japanese Medaka. J. Japan Soc. Water Environ., 26, 671-676.

16) Van den Belt, K., Verheyen, R. and Writters, H. (2003) Comparison of vitellogenin responses in zebrafish and rainbow trout following exposure to environmental estrogens. Ecotoxicol. Environ. Saf., 56, 271-281.

17) Satoh, K., Nagai, F. and Aoki, N. (2001) Several environmental pollutants have binding affinities for both androgen receptor and estrogen receptor $\alpha . J$. Health Sci., 47, 495-501.

18) Satoh, K. and Nagai, F. (2002) Competitive binding 
of alkylphenols to human estrogen and androgen receptors. Ann. Rep. Tokyo Metr. Res. Lab. P. H., 53, 265-267.

19) Paris, F., Balaguer, P., Terouanne, B., Servant, N., Lacoste, C., Cravedi, J. P., Nicolas, J. C. and Sultan, C. (2002) Phenylphenols, biphnols, bisphenol-A and 4-tert-octylphenol exhibit $\alpha$ and $\beta$ estrogen activities and antiandrogen activity in reporter cell lines. Mol. Cell. Endocrinol., 193, 43-49.

20) Satoh, K., Nagai, F., Aoki, N. and Nishijima, M. (2000) Competitive binding of some alkyl $p$ hydroxybenzoates to human estrogen receptor $\alpha$ and B. J. Pharm. Soc. Jpn., 120, 1429-1433.

21) Bayford, J. R., Shaw, L. E., Drew, M. G. B., Pope, G. S., Sauer, M. J. and Darbre, P. D. (2002) Oestrogenic activity of parabens in MCF7 human breast cancer cells. J. Steroid Biol. Mol. Biol., 80, 49-60.

22) Darbre, P. D., Bayford, J. R., Shaw, L. E., Horton, R. A. and Sauer, M. J. (2002) Oestrogenic activity of isobutylparaben in vitro and in vivo. J. Appl. Toxicol., 22, 219-226.

23) Vivacqua, A., Recchia, A. G., Fasanella, G., Gabriele, S., Carpino, A., Rago, V. E., Gioia, M. L., Leggio, A., Bonofiglio, D., Maggiolini, M. and Liguori, A. (2003) The food contaminants bisphenol A and 4-nonylphenol act as agonists for estrogen receptor alpha in MCF7 breast cancer cells. Endocrine, 22, 275-284.

24) Oishi, S. (2001) Effects of butyl paraben on the male productive system in rats. Toxicol. Ind. Health, 217, 31-39.

25) Oishi, S. (2002) Effects of propyl paraben on the male productive system. Food Chem. Toxicol., 40, 1807-1813.

26) Oishi, S. (2002) Effects of butyl paraben on the male productive system in mice. Arch. Toxicol., 76, 423429.

27) Brotons, J. A., Olea-Serrano, M. F., Villalobos, M., Pedraza, V. and Olea, N. (1995) Xenoestrogens released from lacquer coating in food cans. Environ. Health Perspect., 103, 608-612.

28) Skehan, P., Storeng, R., Scudiero, D., Monks, A., McMahon, J., Vistica, D., Wareen, J. T., Bokesch, H., Kenny, S. and Boyd, M. R. (1990) New colorimetric cytotoxicity assay for anticancer-drug screening. J. Natl. Cancer Inst., 82, 1107-1112.

29) Junck, G. A., Svec, H. J., Vick, R. D. and Avery, M. J. (1974) Contamination of water by synthetic polymer tubes. Environ. Sci. Technol., 8, 1100-1106.

30) Isobe, T. and Takada, H. (1998) Behavior and effect of nonylphenol in aquatic environment. J. Japan Soc. Water Environ., 21, 203-208.

31) Suzuki, T., Yaguchi, K., Igarashi, T., Inaba, M., Usami, M. and Yasuda, K. (2002) Monitoring of endocrine disrupting chemicals in well water for drinking and in Tama River at Tama region in Tokyo. Ann. Rep. Tokyo Metr. Res. Lab. P. H., 53, 238243.

32) Tsuda, T. and Kagatsume, T. (2003) Phenolic endocrine disrupters in rivers and lakes in Europe, America and Japan. J. Environ. Chem., 13, 1-16.

33) Tabira, Y., Nakai, M., Asai, D., Yakabe, Y., Tahara, Y., Shinmyozu, T., Noguchi, M., Takatsuki, M. and Shimohigashi, Y. (1999) Structural requirements of para-alkylphenols to bind to estrogen receptor. Eur. J. Biochem., 262, 240-244.

34) Darbre, P. D., Aljarrah, A., Miller, W. R., Coldham, N. G., Sauer, M. J. and Pope, G. S. (2004) Concentrations of parabens in human breast tumors. J. Appl. Toxicol., 24, 5-13. 